Open Access

\title{
The impact of multimorbidity on adult physical and mental health in low- and middle-income countries: what does the study on global ageing and adult health (SAGE) reveal?
}

Perianayagam Arokiasamy ${ }^{1}$, Uttamacharya Uttamacharya ${ }^{1}$, Kshipra Jain ${ }^{1}$, Richard Berko Biritwum²* Alfred Edwin Yawson ${ }^{2}$, Fan Wu ${ }^{3}$, Yanfei Guo ${ }^{3}$, Tamara Maximova ${ }^{4}$, Betty Manrique Espinoza ${ }^{5}$, Aarón Salinas Rodríguez ${ }^{5}$, Sara Afshar ${ }^{6}$, Sanghamitra Pati ${ }^{7}$, Gillian Ice ${ }^{8}$, Sube Banerjee ${ }^{9}$, Melissa A. Liebert ${ }^{10}$, James Josh Snodgrass ${ }^{10}$, Nirmala Naidoo ${ }^{11,12}$, Somnath Chatterji ${ }^{11,12}$ and Paul Kowal ${ }^{12,13}$

\begin{abstract}
Background: Chronic diseases contribute a large share of disease burden in low- and middle-income countries (LMICs). Chronic diseases have a tendency to occur simultaneously and where there are two or more such conditions, this is termed as 'multimorbidity'. Multimorbidity is associated with adverse health outcomes, but limited research has been undertaken in LMICs. Therefore, this study examines the prevalence and correlates of multimorbidity as well as the associations between multimorbidity and self-rated health, activities of daily living $(A D L S)$, quality of life, and depression across six LMICs.
\end{abstract}

Methods: Data was obtained from the WHO's Study on global AGEing and adult health (SAGE) Wave-1 (2007/10). This was a cross-sectional population based survey performed in LMICs, namely China, Ghana, India, Mexico, Russia, and South Africa, including 42,236 adults aged 18 years and older. Multimorbidity was measured as the simultaneous presence of two or more of eight chronic conditions including angina pectoris, arthritis, asthma, chronic lung disease, diabetes mellitus, hypertension, stroke, and vision impairment. Associations with four health outcomes were examined, namely ADL limitation, self-rated health, depression, and a quality of life index. Random-intercept multilevel regression models were used on pooled data from the six countries.

Results: The prevalence of morbidity and multimorbidity was $54.2 \%$ and $21.9 \%$, respectively, in the pooled sample of six countries. Russia had the highest prevalence of multimorbidity (34.7\%) whereas China had the lowest (20.3 \%). The likelihood of multimorbidity was higher in older age groups and was lower in those with higher socioeconomic status. In the pooled sample, the prevalence of 1+ ADL limitation was $14 \%$, depression $5.7 \%$, self-rated poor health $11.6 \%$, and mean quality of life score was 54.4. Substantial cross-country variations were seen in the four health outcome measures. The prevalence of $1+$ ADL limitation, poor self-rated health, and depression increased whereas quality of life declined markedly with an increase in number of diseases.

Conclusions: Findings highlight the challenge of multimorbidity in LMICs, particularly among the lower socioeconomic groups, and the pressing need for reorientation of health care resources considering the distribution of multimorbidity and its adverse effect on health outcomes.

Keywords: Activities of daily living, Low- and middle-income countries, Mental health, Multimorbidity, Non-communicable diseases, Quality of life

\footnotetext{
* Correspondence: biritwum@africaonline.com.gh

${ }^{2}$ Department of Community Health, University of Ghana, Accra, Ghana

Full list of author information is available at the end of the article
} 


\section{Background}

Low- and middle-income countries (LMICs) in the 21st century are witnessing an unprecedented upward shift in life expectancy [1]. This is causing changes in the disease burden profiles of LMICs, with chronic noncommunicable diseases (NCDs) becoming more common and growing public health challenge [2-5]. As a result of increasing longevity, multiple comorbid conditions, commonly referred to as 'multimorbidity', have also become progressively more common among older adults [6-8]. Evidence from both high- and low-income countries indicates that older adults are at much higher risk for multiple chronic diseases [9-14]. At the same time, several recent studies have provided evidence that younger adults also have substantial prevalence of multimorbidity [15-19].

Socioeconomic status (SES) has been found to be strongly associated with the prevalence of multimorbidity, regardless of whether SES is measured through education [20, 21], income [22], occupation [23], or area-based deprivation [24]. In a review of 26 studies on multimorbidity focused on East-Mediterranean countries, Boutayab et al. [25] show that low income, low level of education, and unemployment are associated with higher prevalence of multimorbidity.

Multimorbidity has been associated with adverse health outcomes, such as reduced physical function [26, 27], poor quality of life [28], poor self-rated health (SRH) [29, 30], increased use of inpatient and ambulatory care [13, 31], and mortality [10]. More than two decades ago, Verbrugge et al. [32] demonstrated the exponential increase in disability with increasing numbers of chronic diseases. Multimorbidity also raises the complexities of clinical treatment and patient management, and is consequently associated with higher medical care costs owing to the need for longterm care $[17,33]$. The adverse impact of multimorbidity on other health domains is further exacerbated by socioeconomic deprivation and poorly prepared medical care facilities [34-36].

Studies investigating the prevalence and determinants of multimorbidity have primarily focused on highincome countries (HICs). Multimorbidity studies in LMICs are limited in geographical scope, the number of diseases studied and the effects of multimorbidity (absolute number of diseases or disease combinations) on health outcomes such as physical functioning, quality of life, or mental health $[12,22,25,37,38]$. Of the few existing studies on multimorbidity prevalence from LMICs, Khanam et al. [12] estimated the prevalence of multimorbidity to be $53.8 \%$ among the older adult population of Bangladesh. Alaba and Chola [22] analyzed the adult (aged 18+) population of South Africa and reported $4 \%$ to have multimorbidity, with over 70 $\%$ of these adults being women. The large and growing burden of NCDs in LMICs, particularly when coupled with limitations in resources and competing public health priorities points, to the need to understand the burden of multimorbidity [39, 40].

In the present study, data from the World Health Organization's multi-country Study on global AGEing and adult health (WHO SAGE) Wave 1 was used to investigate two main objectives: 1) to explore the prevalence and SES correlates of multimorbidity in adults, and 2) to examine the associations between multimorbidity and four main health outcomes: self-rated overall general health, depression, physical functioning, and subjective well-being.

\section{Hypotheses}

This study aims to test the following hypotheses: 1) LMICs will exhibit a negative association between higher SES and multimorbidity, similar to the evidence from HICs and some developing countries, and 2) multimorbidity will have positive associations with other health-related outcomes, namely lower SRH, depression, limitation in activities of daily living (ADLs), and poorer quality of life.

\section{Data sources}

This study used data from SAGE Wave 1 (2007-2010). SAGE is a longitudinal ageing and health study with nationally representative samples of adults from six countries: China, Ghana, India, Mexico, the Russian Federation, and South Africa. These countries are at different stages of the demographic and epidemiological transitions but are (with the exception of Russia) experiencing a rapid rise in the older adult population [41]. SAGE is designed as a multi-wave panel study representative of the population aged 50 and older, with a smaller cohort of respondents aged 18-49 for comparative purposes. All sampling plans use multistage clustered design samples drawn from an updated frame. Each household and individual is assigned a known non-zero probability of being selected [42]. Household and individual weights were post-stratified to weight up to population distributions by age and sex in each country. Detailed description of study and sample design is provided elsewhere $[42,43]$.

\section{Methods}

\section{Chronic conditions and multimorbidity}

Multimorbidity is defined as the simultaneous presence of two or more chronic physical health conditions. For this analysis, eight chronic health conditions were included, namely angina pectoris, arthritis, asthma, chronic lung disease, diabetes mellitus, hypertension, stroke, and low visual acuity.

Of these eight conditions, diabetes mellitus and stroke were assessed through a question about ever being 
diagnosed with the disease by a health professional. The specific question was, "Have you ever been told by a health professional/doctor that you have (disease name)?"

The prevalence of angina pectoris, arthritis, asthma, and chronic lung disease was derived from a set of symptombased questions, combined with a diagnostic algorithm. The symptomatic questions and algorithm for each of the diseases are presented in the supplementary material (Additional file 1). Additionally, the use of treatment/ medication received in the 12 months prior to interview was indicative of a diagnosis and was included in prevalence estimates for each disease. Prevalence of angina, arthritis, and asthma was based on symptom-reporting and diagnostic algorithm, adjusted for treatment/medication received in the 12 months prior to interview.

The assessment of hypertension and visual acuity was based on direct physical examination undertaken at the time of interview. The prevalence of hypertension was based on measured blood pressure (systolic and diastolic) taken with the respondent in a seated position. An average of the second and third of three total readings was used as the outcome. In accordance with WHO/ISH guidelines for the management of hypertension [44], the limit for high systolic blood pressure was $140 \mathrm{~mm} / \mathrm{hg}$ or above, and for diastolic blood pressure 90 $\mathrm{mm} / \mathrm{hg}$ or above. An individual was considered to be hypertensive if average systolic or diastolic blood pressure readings exceeded either of these thresholds or they reported current treatment for hypertension.

Visual acuity was measured for both near and distance vision in each eye using a tumbling "E" logMAR chart [45]. Measured near and distance visual acuity was classified into normal vision (0.32-1.6 decimal) and low vision (0.01-0.25 decimal) [46]. In this study, a respondent had low vision if they had either low near or distance vision in both eyes.

\section{Health outcomes \\ Self-rated health (SRH)}

The specific question used to assess overall general SRH was, "In general, how would you rate your health today?" A five-point response scale was used: very good, good, moderate, bad, and very bad. For this analysis, bad and very bad health responses were combined as 'poor health' and remaining categories combined into 'good health' to generate a dichotomous health variable. Poor $\mathrm{SRH}$ is the outcome used in the analysis.

\section{Physical functioning: activities of daily living (ADL)}

Limitation in ADL was used to assess physical functioning. The questions were based on self- reported difficulty in engaging in activities during the last 30 days, using a five-point response scale ranging from none to extreme difficulty. The ADL measure included in SAGE was based on WHODAS 2.0 and has been validated in LMICs by WHO and collaborating agencies [47]. WHODAS 2.0 is validated cross-culturally through a systematic research study. The cross-cultural applicability research study used various qualitative methods to explore the nature and practice of health status assessment in different cultures. The study included linguistic analysis of health-related terminology, key informant interviews, focus groups, and quasi-quantitative methods such as pile sorting and concept mapping (carried out in tandem). Information was gathered on the conceptualization of disability and on important areas of day-to-day functioning.

In this study, severe and extreme difficulties were combined to represent limitation in a particular activity. We have used an extended set of ADL that included sitting for long periods, walking $100 \mathrm{~m}$, standing up, standing for long periods, climbing one flight of stairs, stooping/kneeling/crouching, picking up things with fingers, extending arms above shoulders, concentrating for $10 \mathrm{~min}$, walking a long distance $(1 \mathrm{~km})$, bathing, getting dressed, carrying things, moving around inside home, getting up from lying down, and getting to and using the toilet. For the analysis, a dichotomous variable was created, which took value 1 if the respondent noted a limitation in one or more of the above ADLs (1+ADL) and 0 otherwise.

\section{Quality of life}

The 8-item WHO Quality of Life (WHOQoL) instrument was used to quantify quality of life and included two questions in each of four broad domains: physical, psychological, social, and environmental [48]. Quality of life was assessed by asking respondents to rate their satisfaction with different domains of their lives, such as with money, health, and relationships, as well as rating their overall life satisfaction, using a five-point response scale, ranging from very satisfied to very dissatisfied. A composite score was created by summing the responses across the different questions and rescaling the result from 0-100 where a higher score indicated better quality of life.

\section{Mental health}

Depression was used as a measure of mental health. Depression was assessed through a set of symptomatic questions based on the World Mental Health Survey version of the Composite International Diagnostic Interview [49]. Diagnosis of major depressive episode was derived from an algorithm that accounted for reporting symptoms of depression during the past 12 months [50]. The detailed symptomatic questions and algorithm are provided in the supplementary material (Additional file 1). Prevalence was based on the result of the diagnostic algorithm, adjusting for treatment received. 
Indicators of socioeconomic status and control variables

Years of schooling and household wealth quintile were used to represent SES. For analytical convenience, the highest number of years of education completed was grouped into four categories: no formal schooling, 1-5 years, 6-9 years, and 10 or more years of schooling. In addition to education, household wealth was used as an alternate measure of SES. A wealth index was derived from the household ownership of durable goods, dwelling characteristics (type of floors, walls and cooking stove), and access to services such as improved water, sanitation, and cooking fuel. The detailed list of items is given in the supplementary material (Additional file 1). The results were recoded into dichotomous variables taking the value of 0 if the household did not possess or have access to the good or service, and 1 if it did. A pure random effect model was used to estimate assets per household, then an 'asset ladder' was generated for each country [51]. Using a Bayesian post-estimation (empirical Bayes) method, households were arranged on the asset ladder, where the raw continuous income estimates were transformed in the final step into quintiles.

Two sets of control variables, demographic factors and health risk factors, were included in this study. The demographic variables included: age groups $(18-49,50-$ $59,60-69,70+$ ), locality (urban or rural), sex (men or women), and marital status (currently married/cohabiting or all other). The health risk variables consisted of tobacco use [current users (daily or non-daily) or non-user]; alcohol consumption [current user (consumed 1-4 days/week in the last 12 months) or non-user]; physical activity (active [involved in $150+$ minutes of vigorous activity or $300+$ minutes of moderate activity per week] or otherwise inactive); high risk waist-to-hip ratio (cutoff point: $\geq 0.90$ for men and $\geq 0.85$ for women); and obesity classification (BMI $\geq 30$ ).

\section{Statistical methods}

A two-stage statistical analysis was undertaken; first, the correlates of any morbidity and multimorbidity (2+ chronic diseases) were examined using a multinomial logit model. Second, the association between multimorbidity and the four primary health outcomes were examined: 1+ ADL, presence of depression, poor SRH, and low WHOQoL score. Of the four health outcomes, three were binary variables, 1+ ADL limitation, depression, and poor SRH; therefore, logit models were used to examine the association of morbidity with these indicators. Linear regression was used to investigate associations with the WHOQoL index. All regressions were run on the pooled data from the six countries and therefore estimated in a multilevel framework. Random intercept multilevel (three-level) models were used, where country was the highest level, state/province of residence the second level, and individuals the first level. All analyses were carried out in STATA 12.0. The estimates were considered significant if $P<0.10$.

\section{Ethical approval}

SAGE was approved by the World Health Organization's Ethical Review Committee. Additionally, partner organizations in each country implementing SAGE obtained ethical clearance through their respective institutional review bodies.

\section{Informed consent}

Written informed consent was obtained from all study participants.

\section{Results}

\section{Sample characteristics}

This study analyzed data from 42,236 adults (18,243 men and 23,993 women) aged $\geq 18$ years from WHO SAGE Wave 1 in China, Ghana, India, Mexico, Russia, and South Africa. Table 1 presents the percentage distribution of socioeconomic and demographic characteristics of the study population from each country. Among the countries, the Russian Federation had the highest percentage of population aged 70 years and above (12.5 $\%)$ compared to less than $10 \%$ for the other countries. The proportion living in rural areas ranged from $19 \%$ in Russia to $75 \%$ in India. The percentage of population with no formal schooling was highest in India (36.2 \%) followed by Ghana $(32.7 \%)$ and lowest for Russia $(0.3 \%)$. The percentage of population with $10+$ years of schooling was highest in Russia (87 \%) compared to less than $30 \%$ for Ghana (29.4\%), India (26.8 \%), and Mexico (25.7 \%).

\section{Prevalence of multimorbidity and the primary health outcome measures}

Table 2 shows the prevalence of having any single chronic disease, multimorbidity ( $2+$ chronic diseases), $1+\mathrm{ADL}$ limitation, depression, poor SRH, and low mean WHOQoL index based on the pooled sample of the six SAGE countries. Overall, the prevalence of morbidity - defined as the presence of at least one of the eight chronic diseases - was $54.2 \%$. The prevalence of having at least one chronic disease was highest in South Africa (69.4\%) followed by Ghana (62.1\%), and lowest in India (51.6 \%). The overall prevalence of multimorbidity was $21.9 \%$. Among the six countries, Russia had the highest prevalence of multimorbidity (34.7\%) and the lowest was observed in China (20.3\%); the remaining four countries had a multimorbidity prevalence of approximately $22 \%$.

The prevalence of any single condition and of multimorbidity increased with each progressively older age group; $87 \%$ of the population in the oldest age group $(70+)$ had at least one chronic disease and $60.7 \%$ had 
Table 1 Percent distribution of selected socio-demographic characteristics, by country and for the pooled sample, WHO SAGE Wave $1(2007 / 10)$

\begin{tabular}{|c|c|c|c|c|c|c|c|c|c|}
\hline & China & Ghana & India & Mexico & Russia & South Africa & All countries, total (pooled) & Men (pooled) & Women (pooled) \\
\hline $\mathrm{N}$ & 14,793 & 5108 & 11,230 & 2732 & 4152 & 4221 & 42,236 & 18,243 & 23,993 \\
\hline \multicolumn{10}{|l|}{ Age Group } \\
\hline $18-49$ & 74.2 & 75.4 & 75.2 & 73.6 & 58.7 & 75.9 & 70.7 & 71.8 & 69.5 \\
\hline $50-59$ & 11.6 & 9.8 & 12.0 & 12.7 & 18.7 & 12.0 & 14.6 & 14.5 & 14.7 \\
\hline $60-69$ & 8.2 & 6.8 & 7.7 & 6.8 & 10.2 & 7.4 & 8.4 & 8.2 & 8.6 \\
\hline $70+$ & 6.0 & 8.1 & 5.1 & 7.0 & 12.5 & 4.7 & 6.4 & 5.6 & 7.2 \\
\hline \multicolumn{10}{|l|}{ Sex } \\
\hline Male & 50.9 & 50.0 & 50.9 & 48.0 & 45.0 & 47.2 & 50.7 & - & - \\
\hline Female & 49.1 & 50.0 & 49.1 & 52.0 & 55.0 & 52.8 & 49.3 & - & - \\
\hline \multicolumn{10}{|l|}{ Residence } \\
\hline Urban & 48.5 & 45.8 & 25.5 & 77.8 & 81.5 & 69.3 & 44.6 & 44.0 & 45.2 \\
\hline Rural & 51.5 & 54.2 & 74.5 & 22.2 & 18.5 & 30.7 & 55.4 & 56.0 & 54.8 \\
\hline \multicolumn{10}{|l|}{ Marital status } \\
\hline Never married & 5.7 & 8.4 & 9.4 & 21.3 & 12.8 & 31 & 8.4 & 10.5 & 6.3 \\
\hline Currently married/Cohabiting & 89.0 & 72.6 & 81.9 & 69.6 & 61.1 & 52.8 & 83.3 & 85.3 & 81.3 \\
\hline Widowed/Divorced/Separated & 5.3 & 19.0 & 8.7 & 9.1 & 26.0 & 16.1 & 8.3 & 4.2 & 12.4 \\
\hline \multicolumn{10}{|l|}{ Years of schooling } \\
\hline No formal schooling & 8.4 & 32.7 & 36.2 & 5.9 & 0.3 & 7.8 & 18.3 & 11.3 & 25.6 \\
\hline $1-5$ years & 16.0 & 9.6 & 17.6 & 20.2 & 2.4 & 15.1 & 16.2 & 15.6 & 16.9 \\
\hline $6-9$ years & 46.2 & 18.9 & 19.4 & 48.3 & 10.3 & 26.9 & 33.5 & 35.6 & 31.5 \\
\hline $10+$ years & 29.4 & 38.8 & 26.8 & 25.7 & 87.0 & 50.2 & 31.9 & 37.6 & 26.1 \\
\hline \multicolumn{10}{|l|}{ Wealth quintile } \\
\hline Lowest & 9.8 & 15.3 & 20.6 & 16.5 & 12.7 & 18.9 & 14.3 & 14.5 & 14.1 \\
\hline Second & 15.9 & 17.9 & 21.2 & 23.3 & 12.8 & 19.5 & 17.9 & 17.7 & 18.0 \\
\hline Middle & 18.3 & 19.1 & 19.9 & 20.1 & 16.5 & 20.5 & 19.0 & 20.1 & 17.9 \\
\hline Fourth & 23.4 & 22.6 & 18.0 & 15.4 & 23.5 & 19.4 & 21.3 & 20.7 & 21.8 \\
\hline Highest & 32.6 & 25.2 & 20.2 & 24.6 & 34.5 & 21.8 & 27.6 & 27.0 & 28.2 \\
\hline
\end{tabular}

Results are weighted using pooled sampling weights

multimorbidity. Similarly, the prevalence of single morbidity and multimorbidity was consistently higher in those with lower levels of education and wealth, and lower in those with higher education and wealth (Table 2). For example, prevalence of multimorbidity was $35.2 \%$ and any one morbidity was $66.0 \%$ among adults with no formal schooling compared to $16.0 \%$ and $45.3 \%$ prevalence among adults with $10+$ years of schooling.

Overall, $14 \%$ of respondents had $1+$ ADL limitation, $5.7 \%$ had depression, $11.6 \%$ reported poor SRH, and the mean WHOQoL score was 54.4 (on the scale of 0 to 100). Poorer health outcomes were generally more prevalent at older ages, in women, in rural dwellers, at lower SES, and with larger numbers of comorbid conditions. While considerable cross-country variations were observed in the prevalence of $1+\mathrm{ADL}$, depression, poor
$\mathrm{SRH}$, and low mean WHOQoL scores, the overall patterns were consistent.

Table 2 also shows the prevalence of the four health outcomes among adults with different numbers of chronic conditions. With increasing numbers of chronic conditions, each of the four health outcome measures became worse. For instance, the percentage of adults with $1+\mathrm{ADL}$ increased eight-fold (from $7.1 \%$ to $58.7 \%$ ), depression prevalence increased by nine-fold (3.2 \% to $27 \%$ ), poor SRH increased six-fold (from $5.8 \%$ to $50 \%$ ), and the mean WHOQoL score declined from 57.0 to 43.3 in those with no chronic diseases compared to those with four or more conditions, respectively.

\section{Associations between SES and multimorbidity}

Both measures of SES were negatively associated with $1+\mathrm{ADL}$, depression, and poor SRH, while positively 
Table 2 Prevalence of any morbidity, multimorbidity, and four health outcome measures by background characteristics, WHO-SAGE Wave $1(2007 / 10)$

\begin{tabular}{|c|c|c|c|c|c|c|}
\hline Background variables & $\begin{array}{l}\text { Any morbidity, } \\
\%(95 \% \mathrm{Cl})\end{array}$ & $\begin{array}{l}\text { Multimorbidity, } \\
\%(95 \% \mathrm{Cl})\end{array}$ & $\begin{array}{l}\text { 1+ ADL, } \\
\%(95 \% \mathrm{Cl})\end{array}$ & $\begin{array}{l}\text { Depression, } \\
\%(95 \% \mathrm{Cl}) \\
\end{array}$ & $\begin{array}{l}\text { Poor self-rated health, } \\
\%(95 \% \mathrm{Cl})\end{array}$ & $\begin{array}{l}\text { Mean WHOQOL } \\
\text { score }(95 \% \mathrm{Cl})\end{array}$ \\
\hline \multicolumn{7}{|l|}{ Age group } \\
\hline $18-49$ & $43.8(41.9-45.7)$ & $12.3(11.3-13.5)$ & $9.1(8.2-10.0)$ & $4.9(4.2-5.7)$ & $7.4(6.5-8.5)$ & $55.4(54.9-55.9)$ \\
\hline $50-59$ & $73.5(71.7-75.2)$ & $34.8(33.1-36.4)$ & $16.8(15.5-18.3)$ & $6.4(5.1-7.9)$ & $16.2(15.0-17.5)$ & $53.3(52.8-53.8)$ \\
\hline $60-69$ & $83.5(82.1-84.8)$ & $50.1(48.5-51.7)$ & $27.7(25.9-29.6)$ & $8.2(7.2-9.3)$ & $22.3(20.6-24.1)$ & $51.5(50.8-52.3)$ \\
\hline $70+$ & $87.7(85.8-89.4)$ & $60.7(58.4-62.9)$ & $44(41.7-46.4)$ & $9.6(8.4-10.9)$ & $33.6(31.6-35.6)$ & $49.2(48.4-50.0)$ \\
\hline \multicolumn{7}{|l|}{ Sex } \\
\hline Male & $53.3(51.1-55.5)$ & $19.0(17.7-20.3)$ & $10.1(9.1-11.2)$ & $4.7(4.0-5.6)$ & $10.1(9.1-11.3)$ & $55.1(54.6-55.7)$ \\
\hline Female & $55.2(53.3-57.0)$ & $24.8(23.5-26.2)$ & $18(16.8-19.2)$ & $6.7(5.9-7.5)$ & $13.1(12.2-14.1)$ & $53.7(53.1-54.2)$ \\
\hline \multicolumn{7}{|l|}{ Residence } \\
\hline Urban & $51.3(48.7-54.0)$ & $20.5(18.8-22.4)$ & $10.0(8.7-11.4)$ & $5.0(3.9-6.4)$ & $8.4(7.5-9.4)$ & $55.5(54.7-56.2)$ \\
\hline Rural & $56.6(54.8-58.4)$ & $22.9(21.9-24.1)$ & $17.2(16.2-18.3)$ & $6.2(5.6-7.0)$ & $14.2(13.1-15.3)$ & $53.5(53.0-54.1)$ \\
\hline \multicolumn{7}{|l|}{ Years of schooling } \\
\hline No schooling & $66.0(63.7-68.2)$ & $35.2(33.2-37.3)$ & $33.6(31.4-35.9)$ & $12.0(10.6-13.5)$ & $18.6(17.2-20.1)$ & $51.0(50.1-51.9)$ \\
\hline $1-5$ years & $63.0(60.3-65.6)$ & $28.0(25.6-30.6)$ & $18.7(16.5-21.1)$ & $5.8(4.7-7.2)$ & $18.6(16.2-21.2)$ & $51.7(50.9-52.5)$ \\
\hline $6-9$ years & $52.3(49.8-54.8)$ & $17.5(16.0-19.0)$ & $8.7(7.6-9.9)$ & $4.3(3.5-5.4)$ & $10.6(9.2-12.2)$ & $54.3(53.7-54.9)$ \\
\hline $10+$ years & $45.3(42.3-48.4)$ & $16.0(14.0-18.3)$ & $6.3(5.5-7.2)$ & $3.7(2.9-4.6)$ & $5.2(4.4-6.2)$ & $57.5(56.8-58.3)$ \\
\hline \multicolumn{7}{|l|}{ Wealth quintile } \\
\hline Lowest & $59.4(56.7-62.0)$ & $28.2(25.9-30.7)$ & $24.2(21.7-26.9)$ & $8.5(7.0-10.2)$ & $19.4(17.3-21.6)$ & $48.0(47.2-48.8)$ \\
\hline Second & $57(53.9-60.1)$ & $23.6(21.6-25.6)$ & $18.5(16.5-20.6)$ & $6.7(5.6-8.0)$ & $15(13.3-16.8)$ & $52.1(51.4-52.8)$ \\
\hline Middle & $55.7(51.8-59.6)$ & $22.0(19.9-24.3)$ & $14.3(12.8-16.0)$ & $6.5(5.4-7.8)$ & $13.9(12.3-15.6)$ & $53.7(53.0-54.5)$ \\
\hline Fourth & $56.9(53.4-60.4)$ & $21.9(19.9-24.0)$ & $11.1(9.8-12.6)$ & $5.2(4.0-6.7)$ & $10.2(8.7-12.0)$ & $55.6(54.8-56.4)$ \\
\hline Highest & $46.7(43.8-49.6)$ & $17.3(15.3-19.4)$ & $7.6(6.6-8.7)$ & $3.5(2.8-4.3)$ & $4.9(4.0-6.0)$ & $58.7(58.0-59.4)$ \\
\hline \multicolumn{7}{|l|}{ Country } \\
\hline China & $55(52.5-57.4)$ & $20.3(19.1-21.7)$ & $5.6(4.9-6.2)$ & $1.6(1.2-2.2)$ & $12.5(11.4-13.6)$ & $54.9(54.2-55.6)$ \\
\hline Ghana & $62.1(58.6-65.4)$ & $22.0(19.3-25.1)$ & $16.7(14.7-18.9)$ & $5.2(4.0-6.7)$ & $8.9(7.4-10.8)$ & $52.3(51.4-53.1)$ \\
\hline India & $51.6(49.8-53.4)$ & $22.0(20.5-23.5)$ & $26.2(24.6-27.9)$ & $11.6(10.1-13.2)$ & $10.9(9.8-12.1)$ & $53.7(53.1-54.4)$ \\
\hline Mexico & $52.7(45.2-60.0)$ & $22.1(18.2-26.4)$ & $19.0(14.6-24.4)$ & $9.3(6.5-13.1)$ & $6.9(4.6-10.2)$ & $55.3(53.8-56.9)$ \\
\hline Russia & $59.7(51.6-67.3)$ & $34.7(27.4-42.8)$ & $11.6(9.4-14.1)$ & $4.9(3.6-6.7)$ & $11.3(8.6-14.7)$ & $53.5(52.2-54.9)$ \\
\hline South Africa & $69.4(62.2-75.8)$ & $22.5(18.2-27.4)$ & $19.4(14.9-24.9)$ & $5.0(2.5-9.9)$ & $9.7(7.0-13.3)$ & $53.8(51.7-55.8)$ \\
\hline \multicolumn{7}{|l|}{ Number of diseases } \\
\hline 0 & - & - & $7.1(6.2-8.1)$ & $3.2(2.5-4.0)$ & $5.8(4.9-7.0)$ & $57.0(56.3-57.6)$ \\
\hline 1 & - & - & $11.6(10.6-12.6)$ & $4.7(3.9-5.7)$ & $10.1(8.9-11.4)$ & $54.3(53.7-54.9)$ \\
\hline 2 & - & - & $25.0(22.6-27.4)$ & $9.8(8.2-11.6)$ & $18.7(16.8-20.7)$ & $51.0(50.2-51.8)$ \\
\hline 3 & - & - & $37.1(33.5-40.8)$ & $12.3(10.1-14.9)$ & $33.5(30.2-36.9)$ & $47.0(45.9-48.0)$ \\
\hline $4+$ & - & - & $58.7(53.4-63.8)$ & $27.0(22.1-32.4)$ & $50.0(45.2-54.7)$ & $43.3(42.0-44.6)$ \\
\hline Total & $54.2(52.7-55.8)$ & $21.9(20.9-22.9)$ & $14.0(13.2-14.8)$ & $5.7(5.0-6.4)$ & $11.6(10.9-12.4)$ & $54.4(53.9-54.9)$ \\
\hline
\end{tabular}

Percentage estimates are weighted by the pooled country weight. Higher WHOQoL score indicates better quality of life (on a scale of 0 to 100)

associated with WHOQoL score (Table 2). For example, $33.6 \%$ of respondents with no formal education had $1+$ ADL compared to $6.3 \%$ in those with $10+$ years of schooling. The prevalence of depression was $12 \%$ in the no formal schooling group versus $3.7 \%$ in $10+$ years schooling group, while poor SRH was $18.6 \%$ in the no formal schooling group versus $5.2 \%$ in the $10+$ years of schooling group. Mean WHOQoL index score was worse (51.0) for respondents with no formal schooling compared to 57.5 for those with $10+$ years of schooling. A similar pattern was observed for household wealth quintiles. 
Figure 1 presents the prevalence of multimorbidity by years of schooling completed and household wealth quintiles, and by country. Years of schooling completed showed a pronounced negative association with the prevalence of multimorbidity for all countries, with the largest differences observed in Mexico and Russia. Small differences were seen in the prevalence of multimorbidity across wealth quintiles in all countries except Russia.

\section{Correlates of chronic disease and multimorbidity}

Table 3 presents the estimates of multilevel multinomial logistic regression models used to examine the association of socioeconomic, demographic, and health risk factors with multimorbidity. The dependent variable had three categories: no disease, one disease, and $2+$ diseases (multimorbidity). The 'no disease' category was considered as the reference group in the multinomial logit regression model. Table 3 shows that the relative risks of both one disease and multimorbidity (2+ diseases) increased at each higher age group compared to no disease. For example, compared to the 18-49 age group, adults in the $70+$ age group were four times $(R R R=4.04)$ more likely to have one disease, and almost 18 times $(\mathrm{RRR}=$ 17.9) more likely to have multimorbidity relative to no disease. Compared with men, women were significantly more likely $(\mathrm{RRR}=1.26)$ to have multimorbidity than no disease. Adults living in rural areas were less likely than urban dwellers $(R R R=0.95)$ to have multimorbidity relative to no disease. Measures of SES, based on years of schooling and wealth quintiles, were negatively associated with both multimorbidity and having one disease. Furthermore, all health risk factors, except tobacco consumption, were significantly associated with higher prevalence of both one disease and multimorbidity.

ADL limitations, poor self-rated health (SRH), depression, and quality of life by number of diseases

Figure 2 shows the patterns of the four health outcomes, by number of chronic conditions and country. Across all figures, there is a consistent pattern of poor health outcomes with an increasing number of chronic conditions.
There is, however, variation by country and domains. The ADL limitations increased sharply and consistently across all six countries with increasing number of diseases; the largest increase was observed in India and the lowest in South Africa. Compared to adults with one or two chronic diseases, the level of depression was substantially higher among adults with three or more chronic diseases. WHOQoL declined steadily (quality of life worsened) and prevalence of poor SRH increased with the number of conditions for all six countries.

\section{Association of multimorbidity with the four health outcome measures}

The effects of multimorbidity on ADL, depression, SRH, and WHOQoL are presented in Table 4. The table shows both adjusted (for control variables) and unadjusted estimates for each of the health outcomes. The count of chronic diseases has a statistically significant negative effect on all four health outcomes. Each health outcome showed poorer results as the number of chronic diseases increased. For ADL limitations, depression and poor $\mathrm{SRH}$, the adjusted and unadjusted odds were similar. Those with three chronic diseases were more than four times as likely to have 1+ ADL, depression, and poor SRH as adults with no diseases. Compared with adults with no disease, those with four or more diseases were almost seven times more likely to have $1+\mathrm{ADL}(\mathrm{OR}=7.21)$, depression $(\mathrm{OR}=7.33)$, and poor SRH $(\mathrm{OR}=7.38)$. The WHOQoL index was an average of eight points lower (adjusted $\beta=-8.93$ ) for adults with three chronic diseases compared to adults with no diseases.

Table 5 presents the regression analyses for the association of individual diseases and disease pairs on each of the subjective health outcomes. In Table 5, the results of Model 1 show the effects of individual chronic diseases on subjective health outcomes, after adjusting for the effects of other diseases and the control variables. Model 2 presents the main effects as well as the interactions of the chronic disease pairs. Results from Model 1 show that all diseases, except hypertension, had statistically

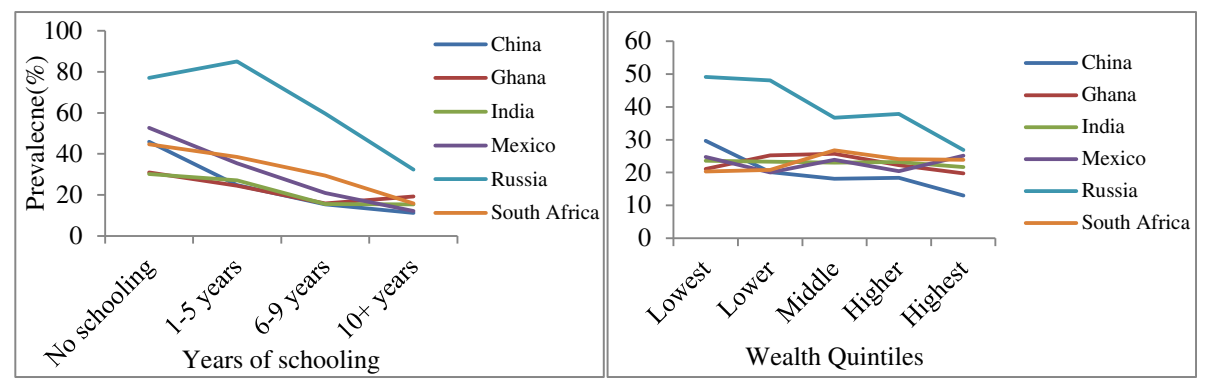

Fig. 1 Prevalence of multimorbidity, by socioeconomic status measures and country, WHO SAGE Wave 1 (2007/10) 
Table 3 Multilevel multinomial logit model estimates examining the correlates of multimorbidity

\begin{tabular}{|c|c|c|}
\hline Variable & $\begin{array}{l}\text { One disease versus } \\
\text { no disease }(95 \% \mathrm{Cl})\end{array}$ & $\begin{array}{l}\text { Multimorbidity versu } \\
\text { no disease }(95 \% \mathrm{Cl})\end{array}$ \\
\hline \multicolumn{3}{|l|}{ Age } \\
\hline \multicolumn{3}{|l|}{$18-49^{R}$} \\
\hline $50-59$ & $2.50^{* * *}(2.31-2.7)$ & $5.10^{* * *}(4.68-5.58)$ \\
\hline $60-69$ & $3.37^{* * *}(3.09-3.71)$ & $10.75^{* * *}(9.73-11.85)$ \\
\hline $70+$ & $4.04 * * *(3.58-4.52)$ & $17.96^{* * *}(15.90-20.22$ \\
\hline \multicolumn{3}{|l|}{ Sex } \\
\hline \multicolumn{3}{|l|}{ Male ${ }^{R}$} \\
\hline Female & $1.04(0.98-1.12)$ & $1.26^{* * *}(1.17-1.35)$ \\
\hline \multicolumn{3}{|l|}{ Residence } \\
\hline \multicolumn{3}{|l|}{ Urban $^{R}$} \\
\hline Rural & $1.04(0.97-1.11)$ & $0.95^{*}(0.88-1.01)$ \\
\hline \multicolumn{3}{|l|}{ Marital status } \\
\hline \multicolumn{3}{|l|}{ Never married ${ }^{R}$} \\
\hline $\begin{array}{l}\text { Currently } \\
\text { married/cohabiting }\end{array}$ & $1.53^{* * *}(1.37-1.72)$ & $1.59 * * *(1.41-1.77)$ \\
\hline Widowed/divorced & $1.74^{* * *}(1.54-2.03)$ & $1.95 * * *(1.71-2.18)$ \\
\hline \multicolumn{3}{|l|}{ Years of schooling } \\
\hline \multicolumn{3}{|l|}{ No formal schooling ${ }^{R}$} \\
\hline $1-5$ years & $0.96(0.87-1.05)$ & $0.92^{* *}(0.83-1.00)$ \\
\hline $6-9$ years & $0.79^{* * *}(0.72-0.86)$ & $0.71^{* * *}(0.64-0.77)$ \\
\hline $10+$ years & $0.71^{* * *}(0.64-0.77)$ & $0.53^{* * *}(0.48-0.59)$ \\
\hline \multicolumn{3}{|l|}{ Wealth quintile } \\
\hline \multicolumn{3}{|l|}{ Lowest $^{R}$} \\
\hline Lower & $1.06(0.95-1.16)$ & $1.02(0.91-1.12)$ \\
\hline Middle & $1.12^{* *}(1.01-1.22)$ & $1.04(0.94-1.14)$ \\
\hline Higher & $1.03(0.94-1.13)$ & $0.92^{*}(0.83-1.02)$ \\
\hline Highest & $1.02(0.92-1.13)$ & $0.87^{* * *}(0.77-0.96)$ \\
\hline \multicolumn{3}{|l|}{ Waist-hip ratio } \\
\hline High risk & $1.12^{* * *}(1.05-1.19)$ & $1.34 * * *(1.26-1.43)$ \\
\hline \multicolumn{3}{|l|}{ Low risk ${ }^{R}$} \\
\hline \multicolumn{3}{|l|}{ Body mass index } \\
\hline Obese & $1.58^{* * *}(1.39-1.76)$ & $2.26^{* * *}(2-2.52)$ \\
\hline \multicolumn{3}{|l|}{ Not obese ${ }^{R}$} \\
\hline \multicolumn{3}{|l|}{ Physical activity } \\
\hline \multicolumn{3}{|l|}{ Active $^{R}$} \\
\hline Inactive & $1.02(0.95-1.1)$ & $1.14 * * *(1.07-1.23)$ \\
\hline \multicolumn{3}{|l|}{$\begin{array}{l}\text { Daily tobacco } \\
\text { consumption }\end{array}$} \\
\hline \multicolumn{3}{|l|}{$\mathrm{No}^{\mathrm{R}}$} \\
\hline Yes & $1.00(0.93-1.08)$ & $1.00(0.93-1.09)$ \\
\hline \multicolumn{3}{|l|}{ Alcohol consumption } \\
\hline \multicolumn{3}{|l|}{$\mathrm{No}^{\mathrm{R}}$} \\
\hline Yes & $1.14^{* * *}(1.04-1.27)$ & $1.12^{* *}(1.01-1.24)$ \\
\hline
\end{tabular}

Table 3 Multilevel multinomial logit model estimates examining the correlates of multimorbidity (Continued)

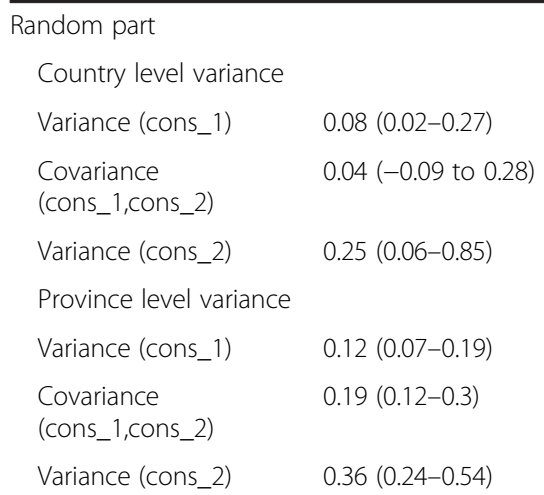

significant negative effects on the subjective health outcomes. For example, adults with arthritis were more than two times as likely to have $1+\mathrm{ADL}$ and depression, and 1.8 times more likely to report poor SRH. The effect on WHOQoL was also negative; the mean score was three points lower among adults with arthritis. The other chronic diseases, including angina, lung diseases, low vision, diabetes, and stroke showed similar negative effects on subjective health outcomes.

Results of Model 2 reveal that the main effects on the different subjective health outcomes for all the conditions except hypertension were significant and negative. Subjective health measures were worse for adults with chronic diseases. The 'main effects' indicate the effect of each disease on a person suffering from none of the other conditions. The interaction estimates for the pairs of diseases showed a mixed pattern. While only a few of the interactions were significant, some of the disease pair interaction terms were positive, and some were negative. A positive interaction (odds ratio greater than one in logit models of $1+$ ADL, depression, and poor $\mathrm{SRH}$ and negative coefficients in linear regressions for WHOQoL) shows that the combined effect of two diseases was more than the additive effect of each one of them individually; while a negative interaction (odds ratio less than one in logit models of $1+\mathrm{ADL}$, depression, and poor SRH and positive coefficients in linear regressions for WHOQoL) indicates that the effect of the two diseases was less than the additive effect of each of them individually. The positive interactions show synergistic effects of the pair of diseases and the negative interactions show antagonistic effects.

Regression results for $1+$ ADL showed that the interactions of nine disease pairs were statistically significant: hypertension-angina, hypertension-diabetes, arthritisangina, arthritis-lung diseases, arthritis-asthma, arthritis- 


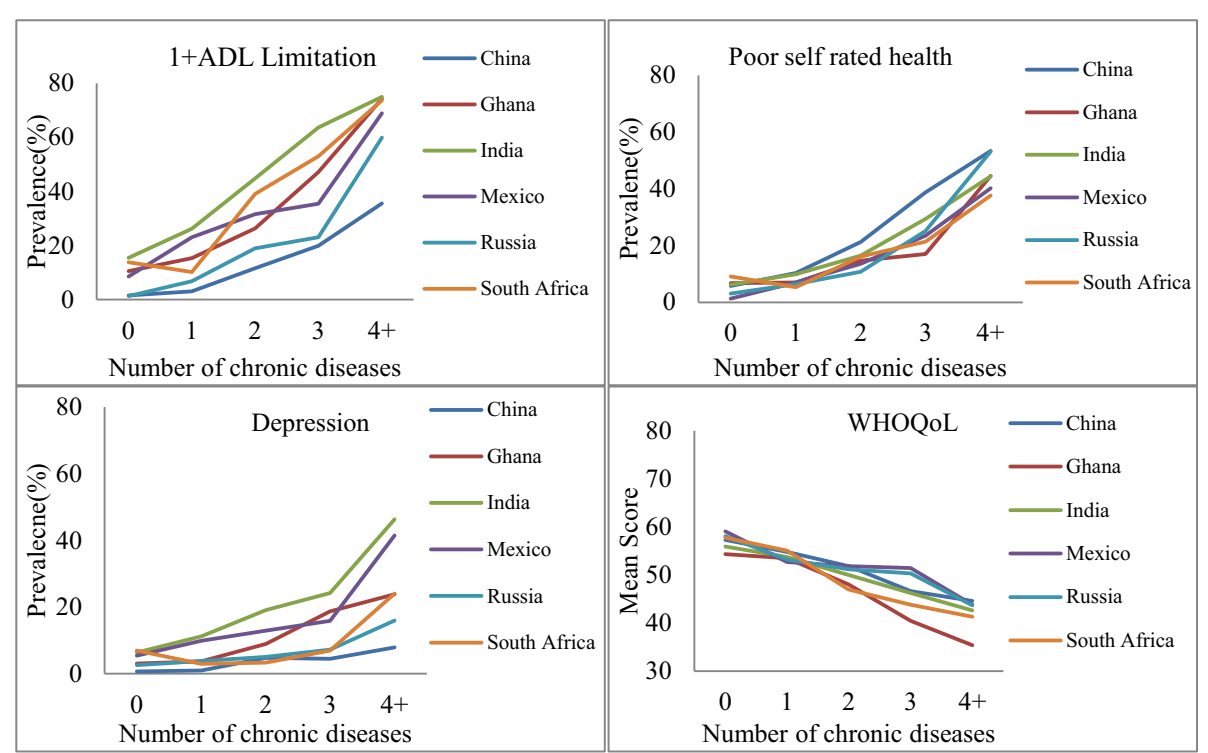

Fig. 2 Prevalence of $1+A D L$ limitations, poor self-rated health, and depression and mean quality of life scores, by count of diseases and country, WHO SAGE Wave $1(2007 / 10)$

low vision, angina-chronic lung diseases, anginaasthma, and low vision-diabetes. Of these nine, the hypertension-diabetes was synergistic. For depression, the interactions of six disease pairs were statistically significant: hypertension-angina, arthritis-angina, arthritischronic lung diseases, angina-diabetes, chronic lung diseases-asthma, and low vision-diabetes; but no synergistic interactions emerged. For poor SRH, interactions with nine disease pairs were statistically significant: hypertension-asthma, arthritis-angina, arthritis-lung diseases, arthritis-asthma, angina-chronic lung disease, angina-low vision, chronic lung diseases-diabetes, asthmadiabetes, and low vision-diabetes. Of these significant interactions, only the hypertension-asthma pairing was synergistically associated with poor SRH. Similarly, for WHOQoL, interactions with seven disease pairs were significant: hypertension-asthma, arthritis-angina, arthritischronic lung disease, arthritis-asthma, arthritis-diabetes, angina-chronic lung diseases, and low vision-diabetes. The pairing of hypertension-asthma showed synergistic interactions with the WHOQoL results.

\section{Discussion}

In this study, the prevalence and correlates of multimorbidity (encompassing eight chronic diseases - angina pectoris, arthritis, asthma, chronic lung disease, diabetes mellitus, hypertension, stroke, and low visual acuity) among adults in six LMICs was assessed. The impact of multimorbidity on four health outcome measures (ADL, depression, SRH, and quality of life) was examined.
The results show that more than half of the sample had at least one chronic disease and around one-fifth had multimorbidity. Among the six countries, Russia had the highest prevalence of multimorbidity (35\%) and China had the lowest (20\%). Ghana, India, Mexico, and South Africa had similar levels of multimorbidity, at around $22 \%$. Further, it may be noted here that the high prevalence of measured hypertension in all six SAGE countries (ranging between $24 \%$ in India to $51 \%$ in South Africa) contributes substantially to the overall prevalence of multimorbidity. A comparative assessment of the multimorbidity with inclusion and exclusion of hypertension demonstrates that, with the exclusion of hypertension, the prevalence of multimorbidity is remarkably lower (21 \% in Russia and $9 \%$ in China) than that with the inclusion of hypertension in multimorbidity measure (Table 1 in Additional file 1).

The prevalence of multimorbidity was lower at higher levels of education in all six countries, demonstrating overall correlation of low SES with multimorbidity. Household wealth was negatively associated with multimorbidity for China and Russia, whereas the other four countries did not show a consistent pattern. The results of negative SES gradient of multimorbidity are consistent with the findings of previous studies $[18,21,26,36]$. The SES gradient for multimorbidity was the sharpest for Russia, while the SES gradient was smallest for Ghana and India. The insignificant or inconsistent pattern of multimorbidity prevalence by household wealth in the lower income countries could be attributed to apparently contrasting socioeconomic patterns of NCD 
Table 4 Multilevel logit model estimates for the effects of disease count on the four health outcome measures, WHO SAGE Wave 1 (2007/10)

\begin{tabular}{|c|c|c|c|c|c|c|c|c|}
\hline \multirow{2}{*}{$\begin{array}{l}\text { Number of } \\
\text { chronic diseases }\end{array}$} & \multicolumn{2}{|l|}{$1+\mathrm{ADL}$} & \multicolumn{2}{|l|}{ Depression } & \multicolumn{2}{|c|}{ Poor self-rated health } & \multicolumn{2}{|l|}{ Mean WHOQoL score } \\
\hline & $\begin{array}{l}\text { Unadjusted OR } \\
(95 \% \mathrm{Cl})\end{array}$ & $\begin{array}{l}\text { Adjusted OR } \\
(95 \% \mathrm{Cl})\end{array}$ & $\begin{array}{l}\text { Unadjusted OR } \\
(95 \% \mathrm{Cl})\end{array}$ & $\begin{array}{l}\text { Adjusted OR } \\
(95 \% \text { Cl) }\end{array}$ & $\begin{array}{l}\text { Unadjusted OR } \\
(95 \% \mathrm{Cl})\end{array}$ & $\begin{array}{l}\text { Adjusted OR } \\
(95 \% \mathrm{Cl})\end{array}$ & $\begin{array}{l}\text { Unadjusted beta } \\
(95 \% \mathrm{Cl})\end{array}$ & $\begin{array}{l}\text { Adjusted beta } \\
(95 \% \mathrm{Cl})\end{array}$ \\
\hline \multicolumn{9}{|l|}{ No disease ${ }^{R}$} \\
\hline \multirow[t]{2}{*}{1 disease } & $2.07^{* * *}$ & $1.51^{* * *}$ & $1.77^{* * *}$ & $1.62^{* * *}$ & $1.90^{* * *}$ & $1.50^{* * *}$ & $-4.26^{* * *}$ & $-1.28^{* * *}$ \\
\hline & $(1.93-2.22)$ & $(1.38-1.65)$ & $(1.57-2.01)$ & $(1.42-1.84)$ & $(1.74-2.08)$ & $(1.35-1.65)$ & $(-4.58$ to -3.94$)$ & $(-1.59$ to -0.98$)$ \\
\hline \multirow[t]{2}{*}{2 diseases } & $4.08^{* * *}$ & $2.47^{* * *}$ & $2.80^{* * *}$ & $2.44^{* * *}$ & $3.38^{* * *}$ & $2.25^{* * *}$ & $-7.38^{* * *}$ & $-3.11^{* * *}$ \\
\hline & $(3.78-4.39)$ & $(2.26-2.72)$ & $(2.48-3.18)$ & $(2.14-2.82)$ & $(3.09-3.69)$ & $(2.03-2.5)$ & $(-7.73$ to -7.03$)$ & $(-3.46$ to -2.77$)$ \\
\hline \multirow[t]{2}{*}{3 diseases } & $7.28^{* * *}$ & $3.81^{* * *}$ & $4.74^{* * *}$ & $4.05^{* * *}$ & $6.33^{* * *}$ & $4.03^{* * *}$ & $-10.74^{* * *}$ & $-5.79^{* * *}$ \\
\hline & $(6.66-7.92)$ & $(3.42-4.26)$ & $(4.12-5.46)$ & $(3.47-4.75)$ & $(5.71-6.98)$ & $(3.59-4.5)$ & $(-11.19$ to -10.28$)$ & $(-6.23$ to -5.35$)$ \\
\hline \multirow[t]{2}{*}{ 4+ diseases } & $15.18^{* * *}$ & $7.21^{* * *}$ & $8.75^{* * *}$ & $7.33^{* * *}$ & $12.3^{* * *}$ & $7.38^{* * *}$ & $-14.6^{* * *}$ & $-8.93^{* * *}$ \\
\hline & (13.58-16.83) & $(6.33-8.17)$ & $(7.53-10.12)$ & $(6.24-8.61)$ & $(10.99-13.71)$ & $(6.43-8.38)$ & $(-15.16$ to -14.03$)$ & $(-9.48$ to -8.38$)$ \\
\hline \multicolumn{9}{|l|}{ Random part } \\
\hline \multirow[t]{2}{*}{ Country } & 0.69 & 1.24 & 0.73 & 0.73 & 0.16 & 0.30 & 7.41 & 5.99 \\
\hline & $(0.17-2.36)$ & $(0.3-4.24)$ & $(0.16-2.52)$ & $(0.16-2.52)$ & $(0.03-0.55)$ & $(0.07-0.97)$ & $(-1.93-16.76)$ & $(-1.24-13.22)$ \\
\hline \multirow[t]{2}{*}{ Province/state } & 0.24 & 0.30 & 0.43 & 0.43 & 0.17 & 0.21 & 8.57 & 3.99 \\
\hline & $(0.16-0.35)$ & $(0.21-0.44)$ & $(0.28-0.64)$ & $(0.28-0.64)$ & $(0.11-0.24)$ & $(0.14-0.3)$ & $(5.68-11.46)$ & $(2.49-5.49)$ \\
\hline Individual & na & na & na & na & na & na & $163.83(161.6-166.0)$ & $120.68(118.9-122.4)$ \\
\hline
\end{tabular}

available in MLWin 
Table 5 Multi-level regression estimates showing the effects of combinations of chronic diseases on the four health outcome measures, WHO SAGE Wave 1 (2007/10)

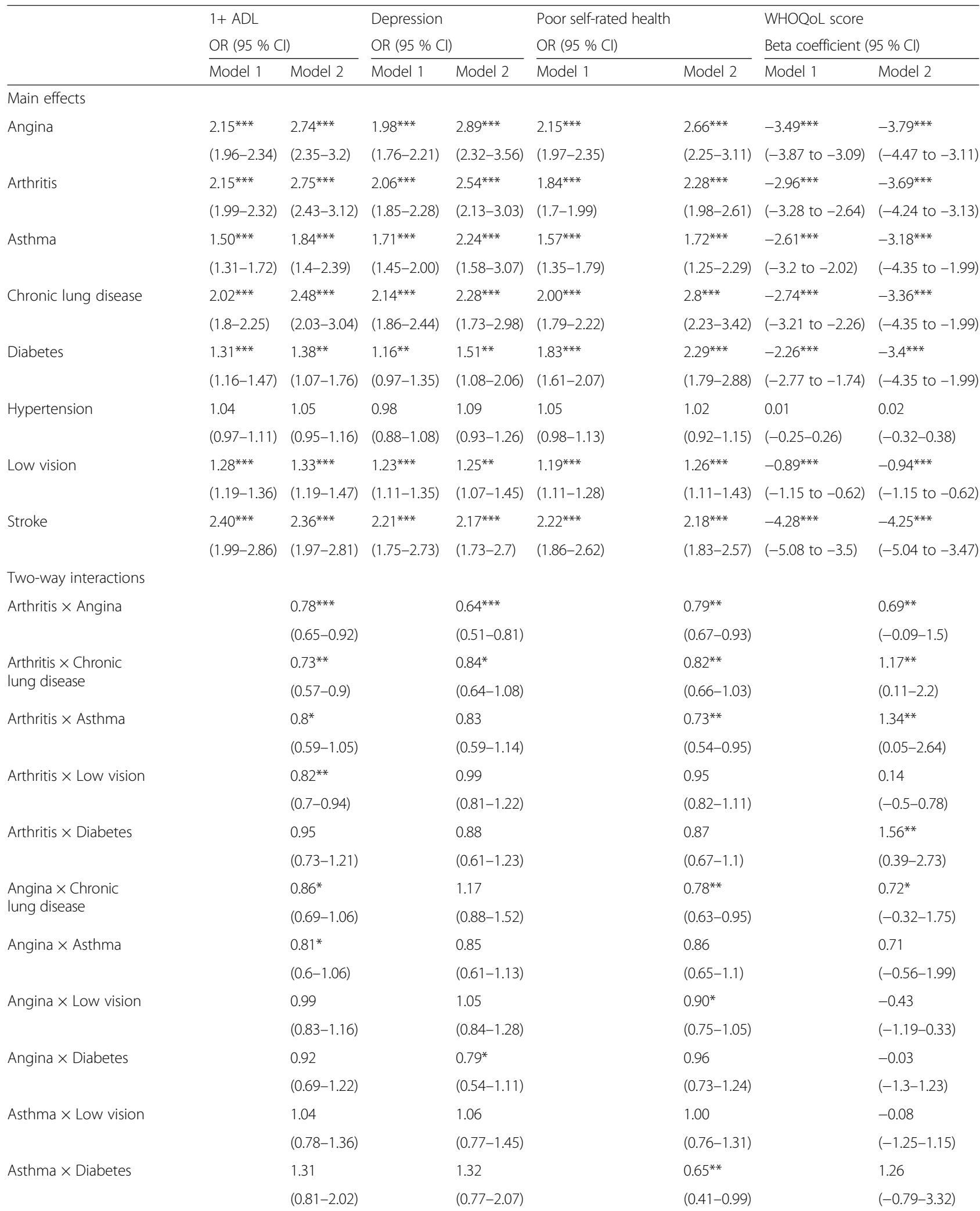


Table 5 Multi-level regression estimates showing the effects of combinations of chronic diseases on the four health outcome measures, WHO SAGE Wave 1 (2007/10) (Continued)

\begin{tabular}{|c|c|c|c|c|c|c|c|c|}
\hline \multirow{2}{*}{\multicolumn{2}{|c|}{ Hypertension $\times$ Arthritis }} & \multicolumn{2}{|l|}{0.96} & \multicolumn{2}{|l|}{1.02} & \multicolumn{2}{|l|}{0.92} & 0.28 \\
\hline & & \multicolumn{2}{|l|}{$(0.83-1.11)$} & \multicolumn{2}{|l|}{$(0.83-1.23)$} & \multicolumn{2}{|l|}{$(0.79-1.06)$} & $(-0.36-0.92)$ \\
\hline \multirow{2}{*}{\multicolumn{2}{|c|}{ Hypertension $\times$ Angina }} & \multicolumn{2}{|l|}{$0.84^{* *}$} & \multicolumn{2}{|l|}{$0.63^{* * *}$} & \multicolumn{2}{|l|}{1.03} & 0.04 \\
\hline & & \multicolumn{2}{|l|}{$(0.7-0.99)$} & \multicolumn{2}{|l|}{$(0.5-0.79)$} & \multicolumn{2}{|l|}{$(0.87-1.22)$} & $(-0.71-0.78)$ \\
\hline \multirow{2}{*}{\multicolumn{2}{|c|}{ Hypertension $\times$ Lung disease }} & \multicolumn{2}{|l|}{0.93} & \multicolumn{2}{|l|}{1.05} & \multicolumn{2}{|l|}{0.93} & -0.10 \\
\hline & & \multicolumn{2}{|l|}{$(0.75-1.17)$} & \multicolumn{2}{|l|}{$(0.8-1.36)$} & \multicolumn{2}{|l|}{$(0.76-1.15)$} & $(-1.05-0.84)$ \\
\hline \multirow{2}{*}{\multicolumn{2}{|c|}{ Hypertension $\times$ Asthma }} & \multicolumn{2}{|l|}{1.02} & \multicolumn{2}{|l|}{1.01} & \multicolumn{2}{|l|}{$1.53^{* * *}$} & $-1.07^{* *}$ \\
\hline & & \multicolumn{2}{|l|}{$(0.77-1.32)$} & \multicolumn{2}{|l|}{$(0.72-1.37)$} & \multicolumn{2}{|l|}{$(1.16-1.99)$} & $(-2.28-0.16)$ \\
\hline \multirow{2}{*}{\multicolumn{2}{|c|}{ Hypertension $\times$ Low vision }} & \multicolumn{2}{|l|}{1.06} & \multicolumn{2}{|l|}{1.01} & \multicolumn{2}{|l|}{1.03} & 0.02 \\
\hline & & $(0.93-1.21)$ & & $(0.84-1.22)$ & & $(0.89-1.19)$ & & $(-0.49-0.55)$ \\
\hline Hypertension $\times$ Diabetes & & $1.25^{* *}$ & & 1.11 & & 1.12 & & -0.37 \\
\hline & & $(0.98-1.57)$ & & $(0.79-1.53)$ & & $(0.87-1.41)$ & & $(-1.4-0.64)$ \\
\hline Low vision $\times$ Diabetes & & $0.74^{* *}$ & & $0.7^{* *}$ & & $0.85^{*}$ & & $1.73^{* * *}$ \\
\hline & & $(0.57-0.92)$ & & $(0.5-0.95)$ & & $(0.66-1.06)$ & & $(0.71-2.73)$ \\
\hline Chronic lung & & 0.86 & & $0.76^{* *}$ & & 0.90 & & 0.54 \\
\hline disease $\times$ Asthma & & $(0.65-1.12)$ & & $(0.54-1.02)$ & & $(0.68-1.17)$ & & $(-0.69-1.77)$ \\
\hline Chronic lung & & 1.10 & & 0.99 & & 0.92 & & -0.30 \\
\hline disease $\times$ Low vision & & $(0.88-1.35)$ & & $(0.76-1.28)$ & & $(0.75-1.12)$ & & $(-1.26-0.64)$ \\
\hline Chronic lung & & 1.05 & & 1.00 & & $0.67^{* *}$ & & 0.39 \\
\hline disease $\times$ Diabetes & & $(0.74-1.48)$ & & $(0.66-1.45)$ & & $(0.47-0.91)$ & & $(-1.23-1.97)$ \\
\hline Random part & & & & & & & & \\
\hline Country & 1.04 & 0.97 & 0.80 & 0.85 & 0.26 & 0.25 & 9.71 & 10.38 \\
\hline & $(0.24-3.56)$ & $(0.21-3.31)$ & $(0.17-2.89)$ & $(0.18-3.02)$ & $(0.05-0.91)$ & $(0.05-0.84)$ & $(2.18-34.24)$ & $(2.35-35.84)$ \\
\hline Province & 0.30 & 0.30 & 0.41 & 0.39 & 0.21 & 0.21 & 3.66 & 3.67 \\
\hline & $(0.2-0.43)$ & $(0.2-0.43)$ & $(0.25-0.63)$ & $(0.24-0.62)$ & $(0.14-0.31)$ & $(0.14-0.31)$ & $(2.5-5.3)$ & $(2.49-5.34)$ \\
\hline Individual & $\mathrm{Na}$ & na & na & na & na & na & $\begin{array}{l}116.5 \\
(114.7-118.4)\end{array}$ & $\begin{array}{l}116.4 \\
(114.5-118.2)\end{array}$ \\
\hline
\end{tabular}

${ }^{*} P<0.1,{ }^{* *} P<0.05,{ }^{* * *} P<0.01$. All models control for background characteristics and health risk factors. na, not applicable. Estimates are obtained through MCMC algorithm available in MLWin; there are total 28 pairs of eight diseases, but we excluded seven interactions with stroke due to the small number of observations

risk factors. Such patterns may arise on account of better access to health care and awareness about prevention and control of NCD risk factors among the wealthier stratum in high- and middle-income countries on one hand, while on the other hand, the wealthier stratum in lower income countries look to have higher levels of health risks like high BMI, high waist-hip ratio, cholesterol, and reduced physical activity [52-55]. Hosseinpoor et al. [56] have shown that the magnitude and direction of socioeconomic inequalities showed different patterns across risk factors such as sex and country income group. The adoption of risky health behaviors tends to transition from higher to lower socioeconomic groups as countries grow richer [57]. Analysis of cross-sectional correlates of multimorbidity suggests that multimorbidity is higher among older adults, women, and those with lower educational levels. These results are consistent with findings from several other studies [18, 36, 58, 59].

These six LMICs studied are home to a large proportion ( $42 \%$ ) of the world's older population: a population at risk of the NCDs included in this study [60-63]. China faces a steep increase in chronic NCDs [64, 65]. India has to deal with an ongoing high burden from infectious and parasitic diseases as well as a rapidly rising burden from chronic diseases [66]. Mexico has seen a 52 $\%$ rise (from $23 \%$ to $75 \%$ ) in the proportion of deaths from NCDs over the last 50 years [67], with NCDs now the leading cause of death and disease, representing 43 $\%$ of deaths and $51 \%$ of disability-adjusted life years [68]. While Ghana has recognized the growing burden of chronic disease since the early 1990s, it is yet to implement a chronic disease policy or an integrated plan to 
deal with the issue [69]. In Russia, in the face of high adult mortality, expectancy began to decline in the mid1960s and continued until the 2000s; such changes were mainly due to mortality from preventable causes, including chronic diseases and related risk factors and a lack of comprehensive disease prevention programs for NCDs [70-73]. South Africa is in the midst of a health transition characterized by a quadruple burden of communicable, non-communicable, and perinatal and maternal diseases, and interpersonal violence [74, 75]. The growing burden of NCDs requires concerted action from each of the governments in these countries.

Overall, the data reported herein indicate that multimorbidity has a significant impact on older adult physical and mental health outcomes in LMICs. The results confirm the negative effect of multimorbidity on quality of life, physical functioning, and mental health in LMICs, as has been previously demonstrated in HICs [26, 76-79]. Studies from HICs have further documented the synergistic effects of multimorbidity and socioeconomic deprivation $[17,78]$; however, in contrast, no significant synergistic effects of number of diseases and socioeconomic deprivation were observed from this analysis (results are not presented).

The published literature suggests interactions between diseases should be considered to estimate contributions to health outcomes [80]; therefore, regression models were used in this study to estimate the effects of individual chronic diseases and disease pairs (interactions) on the four health outcome measures. The estimates revealed a significant and negative independent effect of each of the chronic diseases on ADL limitation, depression, poor SRH, and quality of life. The assessment of interaction effects of chronic disease pairs can help inform strategies for the prevention, control, and treatment of chronic diseases. Among disease pairs, the interaction of hypertension with most other NCDs was more than their additive effect on ADL limitation, SRH, and quality of life. No significant synergistic interaction was found for depression. These results contribute data from LMICs to the emerging evidence base on the nature of disease interactions in multimorbidity [26, 29, 76, 81]. Results also showed significant antagonistic interactions for all measures of health; interaction effects of two chronic diseases is equal to or lower than the combined effects of each of the individual diseases, rather than simple additive effects. These data possibly lend support to evidence that suggests that an individual's level of functioning is reflected not by a simple sum of functioning across domains, but by the impact of diseases on the maximally affected domain and the number of domains affected [82].

The finding that multimorbidity is associated with adverse health outcomes has critical health care implications for people with multimorbidity in LMICs. Persons with multimorbidity need more inpatient and ambulatory care [83-85]. However, patients with multimorbidity also are at higher risk of iatrogenic disease and fragmentation of care because the treatment in such cases is often focused on one chronic condition [86]. Most clinical evidence and guidelines are created by individual disease and rarely account for multimorbidity [87, 88]. Given these results, the management of multimorbidity will surely become a considerable challenge for health systems worldwide [89] and requires an integrated peoplecentered service delivery approach with strengthening of primary health care systems [90]. The challenge is more pressing for LMICs, with health care systems often ill-equipped and largely focused on acute illnesses and maternal and child health care [5, 91].

Noting the potential bias introduced by disease prevalence derived from self-reported physician diagnosis [92-95], this study incorporated a number of alternate methods of estimating disease - using a mixture of selfreported diagnosis, validated symptom reporting-based diagnostic algorithms, and objective health measurements. This makes the findings that multimorbidity is also strongly associated with poor health outcomes in LMICs all the more striking and of major importance in public health and policy terms.

The findings from this study should be viewed in light of important limitations. First, we have used a count of chronic conditions as a measure of multimorbidity, which implies that each of the diseases has equivalent impact on an individual. In reality, the effects of multimorbidity on various domains of health are likely to depend on disease severity, the unique combination of diseases, and access to treatment and support. Second, we have modelled main effects of diseases with interaction terms between disease dyads (Table 5) to assess the effects of each disease pair on each of the four health outcomes. Here, we did not address the interaction of three and higher order interactions due to data limitations (insufficient observations). A third possible limitation relates to the measurement of hypertension in this study. The classification of hypertension based on an average of three measurements at the interval of 1 minute may have contributed to overestimation of hypertension prevalence compared to what may arise from measurement based on regular $24 \mathrm{~h}$ monitoring. Finally, the number of diseases included in this analysis was limited to those included in the SAGE study and, as such, may be missing some higher burden conditions, such as dementia and cancers, which could have resulted in an underestimation of the prevalence and impacts of multimorbidity [96]. However, a number of studies have analyzed multimorbidity using a smaller number of diseases, usually less 
than 10, due to data limitations in LMICs [97, 98]. Regardless, the prevalence found herein is striking and the reality likely to be even more confronting if all health conditions captured.

\section{Conclusions}

The findings provide novel epidemiological evidence of the impact of multimorbidity on selected health outcome measures for six LMICs which have not previously been explored in such detail. Understandably, to date, LMICs have focused on infectious disease, malnutrition, and childhood health. However, these results indicate that there is a growing need to provide effective services for older adults to counter the impact of chronic multimorbidity on physical and mental health. In particular, the high prevalence of ADL limitations indicates the need for services for older adults. More research is required to assess the gaps in the community resources for providing services that maintain quality of life in the face of declining health.

\section{Additional file}

Additional file 1: Symptoms and algorithms. This file contains questions and corresponding algorithms to derive symptom-based prevalence of the chronic conditions assessed in this paper. The file also contains list of variables included for generating household wealth index.

\section{Abbreviations}

ADL: Activities of daily living; HIC: High income countries; LMICs: Low- and middle-income countries; NCD: Non-communicable diseases; RRR: Relative risk ratio; SAGE: Study on Global Ageing and Health; SES: Socioeconomic status; SRH: Self-rated health; WHO: World Health Organization; WHOQoL: World Health Organizations' Quality of Life instrument.

\section{Competing interests}

The authors declare that they have no competing interests.

\section{Authors' contributions}

PA and UU conceived and designed the study; UU carried out the analysis; PA, UU, PK, and KJ drafted the manuscript. All authors reviewed, edited, and contributed to rewriting of the manuscript. All the authors granted final approval to the version submitted for publication.

\section{Authors' information}

Uttamacharya does not use his last name in official documents. But, for technical reasons it is necessary, so we used Uttamacharya as surname and given name.

\section{Acknowledgements}

The authors thank all the respondents who contributed to SAGE and the survey teams. No specific financial support was provided for this analysis. SAGE is supported by WHO and the US National Institute on Aging (NIA) through Interagency Agreements (OGHA 04034785; YA1323-08-CN-0020; Y1-AG-1005-01) and through a research grant (R01-AG034479).

\section{Author details}

${ }^{1}$ International Institute for Population Sciences, Mumbai, India. ${ }^{2}$ Department of Community Health, University of Ghana, Accra, Ghana. ${ }^{3}$ Shanghai Municipal Center for Disease Control and Prevention (CDC), Shanghai, China. ${ }^{4}$ Russian Academy of Medical Sciences (RAMS), Moscow, Russian Federation. ${ }^{5}$ National Institute of Public Health (INSP), Centre for Evaluation Research and Surveys, Cuernavaca, Morelos, Mexico. ${ }^{6}$ Academic Unit of Primary Care and
Population Sciences, Faculty of Medicine, University of Southampton, University Road, Southampton SO17 1BJ, UK. 'Indian Institute of Public Health, Bhubaneswar, Public Health Foundation of India, Bhubaneswar, Odisha, India. ${ }^{8}$ Ohio University, Department of Social Medicine and Director of Global Health, Athens, OH, USA. ${ }^{9}$ Centre for Dementia Studies, Brighton and Sussex Medical School, University of Sussex, Brighton, UK. ${ }^{10}$ University of Oregon, Department of Anthropology, Eugene, OR, USA. ${ }^{11}$ World Health Organization, Statistics Measurement and Analysis Unit, Geneva, Switzerland. ${ }^{12}$ World Health Organization Study on global AGEing and adult health (SAGE), Geneva, Switzerland. ${ }^{13}$ University of Newcastle Priority Research Centre for Gender, Health and Ageing, Newcastle, NSW, Australia.

Received: 16 April 2015 Accepted: 17 June 2015

Published online: 03 August 2015

\section{References}

1. United Nations, Department of Economic and Social Affairs, Population Division. World Population Ageing 2013. ST/ESA/SER.A/348. New York: United Nations; 2013.

2. Quigley MA. Commentary: shifting burden of disease-epidemiological transition in India. Int J Epidemiol. 2006;35:1530-1.

3. Abegunde DO, Mathers CD, Adam T, Ortegon M, Strong K. The burden and costs of chronic diseases in low-income and middle-income countries. Lancet. 2007;370:1929-38.

4. Miranda JJ, Kinra S, Casas JP, Davey Smith G, Ebrahim S. Non-communicable diseases in low- and middle-income countries: context, determinants and health policy. Tropical Med Int Health. 2008;13:1225-34.

5. Ebrahim S, Pearce N, Smeeth L, Casas JP, Jaffar S, Piot P. Tackling non-communicable diseases in low- and middle-income countries: is the evidence from high-income countries all we need? PLoS Med. 2013;10, e1001377.

6. Smith SM, O'Dowd T. Chronic diseases: what happens when they come in multiples? Br J Gen Pract. 2007;57:268-70.

7. Fortin M, Soubhi H, Hudon C, Bayliss EA, van den Akker M. Multimorbidity's many challenges. BMJ. 2007;334:1016-7.

8. Prados-Torres A, Poblador-Plou B, Calderon-Larranaga A, Gimeno-Feliu LA, Gonzalez-Rubio F, Poncel-Falco A, et al. Multimorbidity patterns in primary care: interactions among chronic diseases using factor analysis. PLoS One. 2012; 7, e32190.

9. van den Akker M, Buntinx F, Metsemakers JF, Roos S, Knottnerus JA. Multimorbidity in general practice: prevalence, incidence, and determinants of co-occurring chronic and recurrent diseases. J Clin Epidemiol. 1998:51:367-75.

10. Gijsen R, Hoeymans N, Schellevis FG, Ruwaard D, Satariano WA, van den Bos GA. Causes and consequences of comorbidity: a review. J Clin Epidemiol. 2001;54:661-74.

11. Walker AE. Multiple chronic diseases and quality of life: patterns emerging from a large national sample, Australia. Chronic IIIn. 2007;3:202-18.

12. Khanam MA, Streatfield PK, Kabir ZN, Qiu C, Cornelius C, Wahlin A. Prevalence and patterns of multimorbidity among elderly people in rura Bangladesh: a cross-sectional study. J Health Popul Nutr. 2011;29:406-14.

13. Salisbury C, Johnson L, Purdy S, Valderas JM, Montgomery AA. Epidemiology and impact of multimorbidity in primary care: a retrospective cohort study. Br J Gen Pract. 2011;61:e12-21.

14. Salive ME. Multimorbidity in older adults. Epidemiol Rev. 2013;35:75-83.

15. Mercer SW, Smith SM, Wyke S, O'Dowd T, Watt GC. Multimorbidity in primary care: developing the research agenda. Fam Pract. 2009;26:79-80

16. Taylor AW, Price K, Gill TK, Adams R, Pilkington R, Carrangis N, et al. Multimorbidity - not just an older person's issue. Results from an Australian biomedical study. BMC Public Health. 2010;10:718.

17. Barnett K, Mercer SW, Norbury M, Watt G, Wyke S, Guthrie B. Epidemiology of multimorbidity and implications for health care, research, and medical education: a cross-sectional study. Lancet. 2012;380:37-43.

18. Agborsangaya CB, Lau D, Lahtinen M, Cooke T, Johnson JA. Multimorbidity prevalence and patterns across socioeconomic determinants: a cross-sectional survey. BMC Public Health. 2012;12:201.

19. Pati S, Agrawal S, Swain S, Lee JT, Vellakkal S, Hussain MA, et al. Non-communicable disease multimorbidity and associated health care utilization and expenditures in India: cross-sectional study. BMC Health Serv Res. 2014;14:451. 
20. Uijen AA, van de Lisdonk EH. Multimorbidity in primary care: prevalence and trend over the last 20 years. Eur J Gen Pract. 2008;14:28-32.

21. Schafer I, Hansen H, Schon G, Hofels S, Altiner A, Dahlhaus A, et al. The influence of age, gender and socio-economic status on multimorbidity patterns in primary care. First results from the multicare cohort study. BMC Health Serv Res. 2012;12:89.

22. Alaba O, Chola L. The social determinants of multimorbidity in South Africa. Int J Equity Health. 2013;12:63.

23. Chandola T, Ferrie J, Sacker A, Marmot M. Social inequalities in self-reported health in early old age: follow-up of prospective cohort study. BMJ. 2007;334:990.

24. Mercer SW, Watt GC. The inverse care law: clinical primary care encounters in deprived and affluent areas of Scotland. Ann Fam Med. 2007;5:503-10.

25. Boutayeb A, Boutayeb S, Boutayeb W. Multi-morbidity of non communicable diseases and equity in WHO Eastern Mediterranean countries. Int J Equity Health. 2013;12:60.

26. Fried LP, Bandeen-Roche K, Kasper JD, Guralnik JM. Association of comorbidity with disability in older women: the Women's Health and Aging Study. J Clin Epidemiol. 1999:52:27-37.

27. Kadam UT, Croft PR. Clinical multimorbidity and physical function in older adults: a record and health status linkage study in general practice. Fam Pract. 2007;24:412-9.

28. Fortin M, Lapointe L, Hudon C, Vanasse A, Ntetu AL, Maltais D. Multimorbidity and quality of life in primary care: a systematic review. Health Qual Life Outcomes. 2004;2:51.

29. Galenkamp H, Braam AW, Huisman M, Deeg DJ. Somatic multimorbidity and self-rated health in the older population. J Gerontol B Psychol Sci Soc Sci. 2011;66:380-6.

30. Hoeymans N, Feskens EJ, Kromhout D, van den Bos GA. The contribution of chronic conditions and disabilities to poor self-rated health in elderly men. J Gerontol Ser A Biol Sci Med Sci. 1999;54:M501-6.

31. Wolff JL, Starfield B, Anderson G. Prevalence, expenditures, and complications of multiple chronic conditions in the elderly. Arch Intern Med. 2002;162:2269-76.

32. Verbrugge LM, Lepkowski JM, Imanaka Y. Comorbidity and its impact on disability. Milbank Q. 1989;67:450-84.

33. Parekh AK, Barton MB. The challenge of multiple comorbidity for the US health care system. JAMA. 2010;303:1303-4.

34. Tu HT. Rising health costs, medical debt and chronic conditions. Issue Brief Cent Stud Health Syst Change. 2004;88:1-5.

35. Lehnert T, Heider D, Leicht H, Heinrich S, Corrieri S, Luppa M, et al. Review: health care utilization and costs of elderly persons with multiple chronic conditions. Med Care Res Rev. 2011;68:387-420.

36. Marengoni A, Angleman S, Melis R, Mangialasche F, Karp A, Garmen A, et al. Aging with multimorbidity: a systematic review of the literature. Ageing Res Rev. 2011;10:430-9.

37. Househam KC. Africa's burden of disease: the University of Cape Town sub-Saharan Africa Centre for Chronic Disease. S Afr Med J. 2010;100:94-5.

38. Zeba AN, Delisle HF, Renier G, Savadogo B, Baya B. The double burden of malnutrition and cardiometabolic risk widens the gender and socioeconomic health gap: a study among adults in Burkina Faso (West Africa). Public Health Nutr. 2012;15:2210-9.

39. Nugent R. Chronic diseases: a growing problem in developing countries. Diabetes Voice. 2008;53:17-20.

40. Mendis S. The policy agenda for prevention and control of non-communicable diseases. Br Med Bull. 2010;96:23-43.

41. He W, Muenchrath MN, Kowal P. Shades of gray: a cross-country study of health and well-being of the older populations in SAGE countries, 2007-2010. Washington DC: U.S. Government Printing Office; 2012.

42. Kowal P, Chatterji S, Naidoo N, Biritwum R, Fan W, Lopez Ridaura R, et al Data resource profile: the World Health Organization Study on global AGEing and adult health (SAGE). Int J Epidemiol. 2012;41:1639-49.

43. Naidoo N. WHO Study on global AGEING and adult health (SAGE) Waves 0 and 1 - Sampling information for China, Ghana, India, Mexico, Russia, and South Africa. SAGE Working Paper No 5. Geneva: World Health Organization; 2012.

44. Whitworth JA. World Health Organization/International Society of Hypertension statement on management of hypertension. J Hypertens. 2003;21:1983-92.

45. Virgili G, Acosta R, Grover LL, Bentley SA, Giacomelli G. Reading aids for adults with low vision. Cochrane Database Syst Rev. 2013;10, CD003303.
46. International Council of Ophthalmology. Visual acuity measurement standard. Visual Functions Committee. San Fransisco, CA: ICO; 1984.

47. Ustun TB, Chatterji S, Kostanjsek N, Rehm J, Kennedy C, Epping-Jordan J, et al. Developing the World Health Organization Disability Assessment Schedule 2.0. Bull World Health Organ. 2010;88:815-23.

48. Schmidt S, Muhlan H, Power M. The EUROHIS-QOL 8-item index: psychometric results of a cross-cultural field study. Eur J Pub Health. 2006;16:420-8.

49. Kessler RC, Ustun TB. The World Mental Health (WMH) Survey Initiative Version of the World Health Organization (WHO) Composite International Diagnostic Interview (CIDI). Int J Methods Psychiatr Res. 2004;13:93-121

50. Ayuso-Mateos JL, Nuevo R, Naidoo N, Chatterji S. From depressive symptoms to depressive disorders: the relevance of thresholds. $\mathrm{Br} \mathrm{J}$ Psychiatry J Ment Sci. 2010;196:365-71.

51. Ferguson BD, Tandon A, Gakidou E, Murray CJL. Estimating permanent income using indicator variables. In: Murray $C J L$, Evans DB, editors. Health systems performance assessment: debates, methods and empiricism. Geneva: World Health Organization; 2003.

52. Sobal J, Stunkard AJ. Socioeconomic status and obesity: a review of the literature. Psychol Bull. 1989:105:260-75.

53. Smith KV, Goldman N. Socioeconomic differences in health among older adults in Mexico. Soc Sci Med. 2007:65:1372-85.

54. Dinsa GD, Goryakin Y, Fumagalli E, Suhrcke M. Obesity and socioeconomic status in developing countries: a systematic review. Obes Rev. 2012;13:1067-79.

55. Aitsi-Selmi A, Bell R, Shipley MJ, Marmot MG. Education modifies the association of wealth with obesity in women in middle-income but not low-income countries: an interaction study using seven national datasets, 2005-2010. PLoS One. 2014;9, e90403.

56. Hosseinpoor AR, Bergen N, Kunst A, Harper S, Guthold R, Rekve D, et al. Socioeconomic inequalities in risk factors for non communicable diseases in low-income and middle-income countries: results from the World Health Survey. BMC Public Health. 2012;12:912.

57. Blakely T, Hales S, Kieft C, Wilson N, Woodward A. The global distribution of risk factors by poverty level. Bull World Health Organ. 2005;83:118-26.

58. Kirchberger I, Meisinger C, Heier M, Zimmermann AK, Thorand B, Autenrieth CS, et al. Patterns of multimorbidity in the aged population. Results from the KORA-Age study. PLoS One. 2012;7, e30556.

59. Schram MT, Frijters D, van de Lisdonk EH, Ploemacher J, de Craen AJ, de Waal MW, et al. Setting and registry characteristics affect the prevalence and nature of multimorbidity in the elderly. J Clin Epidemiol. 2008;61:1104-12.

60. Bloom DE, Cafiero ET, Jané-Llopis E, Abrahams-Gessel S, Bloom LR, Fathima S, et al. The global economic burden of non-communicable diseases. Geneva: World Economic Forum; 2011.

61. Dey S, Nambiar D, Lakshmi JK, Sheikh K, Reddy KS. Health of the elderly in India: Challenges of access and affordability. In: Smith P, Majmundar M, editors. Aging in Asia: Findings from new and emerging data initiatives. Washington, DC: National Academies Press; 2012. p. 371-86.

62. Williams R, Krakauer R. The challenge of non-communicable diseases and geriatric conditions. In: Global population ageing: peril or promise? Geneva: World Economic Forum; 2011.

63. National Sample Survey Organisation. Morbidity, Health Care and the Condition of the Aged. National Sample Survey, 60th Round. Report no. 507 (60/25.0/1). New Delhi: Ministry of Statistics and Programme Implementation, Government of India; 2006.

64. Tang S, Ehiri J, Long Q. China's biggest, most neglected health challenge: non-communicable diseases. Infect Dis Poverty. 2013;2:7.

65. Yang G, Kong L, Zhao W, Wan X, Zhai Y, Chen LC, et al. Emergence of chronic non-communicable diseases in China. Lancet. 2008;372:1697-705.

66. Bloom DE, Cafiero ET, McGovern ME, Prettner K, Stanciole A, Weiss J, et al. The economic impact of non-communicable disease in China and India: estimates, projections, and comparisons. PGDA working paper 2013. http:// cdn1.sph.harvard.edu/wp-content/uploads/sites/1288/2013/10/ PGDA_WP_107.pdf.

67. Gonzalez-Pier E, Gutierrez-Delgado C, Stevens G, Barraza-Llorens M, PorrasCondey R, Carvalho N, et al. Priority setting for health interventions in Mexico's System of Social Protection in Health. Lancet. 2006;368:1608-18.

68. Lozano R, Gomez-Dantes H, Garrido-Latorre F, Jimenez-Corona A, Campuzano-Rincon JC, Franco-Marina F, et al. Burden of disease, injuries, 
risk factors and challenges for the health system in Mexico. Publica de Mexico. 2013;55:580-94.

69. Bosu WK. A comprehensive review of the policy and programmatic response to chronic non-communicable disease in Ghana. Ghana Med J. 2012:46:69-78.

70. Chenet L, Leon D, McKee M, Vassin S. Deaths from alcohol and violence in Moscow: socio-economic determinants. Eur J Popul. 1998;14:19-37.

71. Leon DA, Shkolnikov VM. Social stress and the Russian mortality crisis. JAMA. 1998;279:790-1.

72. Notzon FC, Komarov YM, Ermakov SP, Sempos CT, Marks JS, Sempos EV. Causes of declining life expectancy in Russia. JAMA. 1998;279:793-800.

73. Cockerham WC. Healthy lifestyles in Russia. Soc Sci Med. 2000;51:1313-24.

74. Joubert J, Bradshaw D. Population ageing and health challenges in South Africa. In: Fourie J, Steyn K, Temple NJ, Council SAMR, editors. Chronic diseases of lifestyle in South Africa since 1995-2005. Tygerberg: Medical Research Council; 2006.

75. Institute for Health Metrics and Evaluation. GBD 2010 Profile: South Africa. Seattle: IHME; 2013.

76. Fortin M, Dubois MF, Hudon C, Soubhi H, Almirall J. Multimorbidity and quality of life: a closer look. Health Qual Life Outcomes. 2007;5:52.

77. Gunn JM, Ayton DR, Densley K, Pallant JF, Chondros P, Herrman HE, et al. The association between chronic illness, multimorbidity and depressive symptoms in an Australian primary care cohort. Soc Psychiatry Psychiatr Epidemiol. 2012;47:175-84.

78. Lawson KD, Mercer SW, Wyke S, Grieve E, Guthrie B, Watt GC, et al. Double trouble: the impact of multimorbidity and deprivation on preferenceweighted health related quality of life a cross sectional analysis of the Scottish Health Survey. Int J Equity Health. 2013;12:67.

79. Smith DJ, Court H, McLean G, Martin D, Langan Martin J, Guthrie B, et al. Depression and multimorbidity: a cross-sectional study of 1,751,841 patients in primary care. J Clin Psychiatry. 2014;75:1202-8.

80. Stenholm S, Westerlund H, Head J, Hyde M, Kawachi I, Pentti J, et al. Comorbidity and functional trajectories from midlife to old age: The Health and Retirement Study. J Gerontol Ser A Biol Sci Med Sci. 2015;70:332-8.

81. Hunger M, Thorand B, Schunk M, Doring A, Menn P, Peters A, et al. Multimorbidity and health-related quality of life in the older population: results from the German KORA-age study. Health Qual Life Outcomes. 2011;9:53.

82. Gilson BS, Gilson JS, Bergner M, Bobbit RA, Kressel S, Pollard WE, et al. The sickness impact profile. Development of an outcome measure of health care. Am J Public Health. 1975;65:1304-10.

83. Wang HH, Wang JJ, Wong SY, Wong MC, Li FJ, Wang PX, et al. Epidemiology of multimorbidity in China and implications for the healthcare system: cross-sectional survey among 162,464 community household residents in southern China. BMC Med. 2014;12:188.

84. Wang HHX, Wang JJ, Lawson KD, Wong SYS, Wong MCS, Li FJ, et al. Relationships of multimorbidity and income with hospital admissions in 3 health care systems. Ann Fam Med. 2015;13:164-7.

85. Payne RA, Abel GA, Guthrie B, Mercer SW. The effect of physical multimorbidity, mental health conditions and socioeconomic deprivation on unplanned admissions to hospital: a retrospective cohort study. CMAJ. 2013;185:E221-8

86. Guthrie B, Saultz JW, Freeman GK, Haggerty JL. Continuity of care matters. BMJ. 2008;337:a867.

87. van Weel C, Schellevis FG. Comorbidity and guidelines: conflicting interests. Lancet. 2006:367:550-1.

88. Boyd CM, Darer J, Boult C, Fried LP, Boult L, Wu AW. Clinical practice guidelines and quality of care for older patients with multiple comorbid diseases: implications for pay for performance. JAMA. 2005;294:716-24.

89. WHO. The World Health Report 2008: primary healthcare, now more than ever. Geneva, Switzerland: World Health Organization; 2008.

90. Banerjee S. Multimorbidity_older adults need health care that can count past one. Lancet. 2015;385:587-9.

91. WHO. WHO strategy on people-centered and integrated health services. Geneva: World Health Organization; 2014.

92. Allotey P, Davey T, Reidpath DD. NCDs in low- and middle-income countries - assessing the capacity of health systems to respond to population needs. BMC Public Health. 2014;14:S1.

93. Hosseinpoor AR, Bergen N, Mendis S, Harper S, Kunst A, Chatterji S. Socioeconomic inequality in the prevalence of noncommunicable diseases in low- and middle-income countries: results from the World Health Survey. BMC Public Health. 2012;12:474.

94. Basu S, King AC. Disability and chronic disease among older adults in India: detecting vulnerable populations through the WHO SAGE Study. Am J Epidemiol. 2013;178:1620-8.

95. Levesque JF, Mukherjee S, Grimard D, Boivin A, Mishra S. Measuring the prevalence of chronic diseases using population surveys by pooling selfreported symptoms, diagnosis and treatments: results from the World Health Survey of 2003 for South Asia. Int J Public Health. 2013;58:435-47.

96. Vellakkal S, Millett C, Basu S, Khan Z, Aitsi-Selmi A, Stuckler D, et al. Are estimates of socioeconomic inequalities in chronic disease artefactually narrowed by self-reported measures of prevalence in low-income and middle-income countries? Findings from the WHO-SAGE survey. J Epidemiol Community Health. 2015;69:218-25.

97. Diederichs C, Berger K, Bartels DB. The measurement of multiple chronic diseases-a systematic review on existing multimorbidity indices. J Gerontol A: Biol Med Sci. 2011;66:301-11.

98. Violan C, Foguet-Boreu Q, Flores-Mateo G, Salisbury C, Blom J, Freitag M, et al. Prevalence, determinants and patterns of multimorbidity in primary care: a systematic review of observational studies. PLoS One. 2014;9, e102149.

\section{Submit your next manuscript to BioMed Central and take full advantage of:}

- Convenient online submission

- Thorough peer review

- No space constraints or color figure charges

- Immediate publication on acceptance

- Inclusion in PubMed, CAS, Scopus and Google Scholar

- Research which is freely available for redistribution 